\title{
DE LA SUBCONTRATACIÓN LABORAL A LA ECONOMÍA COLABORATIVA: VICISITUDES EN SUS POSIBLES MECANISMOS DE CONTROL INTERNACIONAL ${ }^{1}$
}

\author{
From outsourcing to sharing economy: \\ Challenges in its possible mechanisms of international control
}

Andrea De Vicente Arias*

Universidad del País Vasco / Euskal Herriko Unibertsitatea

\begin{abstract}
RESUMEN
A pesar de ser un fenómeno novedoso, al menos la mayor parte de los problemas de la economía colaborativa en relación a la desprotección de las personas trabajadoras y su regulación son conocidos para el Derecho del Trabajo. Evidentemente el componente digital contribuye a diluir la identificación de los sujetos y elementos constitutivos de una relación laboral, pero es fácil asimilar estas problemáticas a las que presentaba la subcontratación; además, la influencia que la Empresa Trasnacional tiene en su desarrollo es muy comparable. Bajo estas premisas, la economía colaborativa sería poco más que una evolución de los fenómenos ligados a la descentralización productiva, lo que permite explorar las posibilidades y tendencias generales en su regulación internacional a pesar de sus particularidades.
\end{abstract}

Palabras clave: Economía colaborativa, subcontratación, empresas trasnacionales, lex mercatoria

\section{ABSTRACT}

Despite being a new phenomenon, at least most of the issues of the sharing economy related to the lack of protection of workers and their regulation are well known for Labor Law. Obviously, its digital component contributes to dilute the identification of the subjects and constituent elements of an employment relationship, but it is easy to assimilate these problems to those presented by outsourcing; in addition, the influence that the Transnational Corporation has on its development is very comparable. Under these premises, the sharing economy would not be much more than an evolution of those transformations linked to productive decentralization, which helps exploring the possibilities and general tendencies in its international regulation, despite its particularities.

Keywords: Sharing economy, outsourcing, transnational corporations, lex mercatoria

1 Ponencia presentada en el IV Encuentro de Profesionales del Asesoramiento Laboral y Social, celebrado en la Facultad de Relaciones Laborales y Trabajo Social (UPV/EHU-Leioa los días 11 y 12 de abril de 2019 .

\footnotetext{
* Correspondencia a: Andrea De Vicente Arias. Lan Harreman eta Gizarte Langintza Fakultatea/Facultad de Relaciones Laborales y Trabajo Social. Barrio Sarriena s/n. 48940-LEIOA - andrea.devicente@ehu.eus -

Cómo citar: De Vicente Arias, Andrea. (2019). «De la subcontratación laboral a la economía colaborativa: vicisitudes en sus posibles mecanismos de control internacional»; Lan Harremanak, 41, 87-104. (https://doi.org/10.1387/lan-harremanak. 20892).

Recibido: 25 junio, 2019; aceptado: 28 mayo, 2019.

ISSN 1575-7048 - eISSN 2444-5819 / (C) 2019 UPV/EHU
} 


\section{SUMARIO}

1. Concepto y rasgos definitorios de la economia colaborativa: ¿vuelta al origen del problema? - 2. Del trabajo en red al trabajo en la red: algunos apuntes sobre lo novedoso de la organización de la producción.-3. Contexto socioeconómico del desarrollo de la economía colaborativa e influencia de la Empresa Transnacional.-4. Los mecanismos de (des)control internacional de la subcontratación laboral como maco regulador de la economía colaborativa. 4.1. El papel de los Estados y los organismos internacionales en la desprotección de las personas trabajadoras. 4.2. El soft law como espacio regulador de la economía colaborativa. 4.3. Límites de la acción protectora de los marcos supranacionales y tendencias en regulación internas en la actualidad.-5. Conclusiones.-6. Bibliografía

\section{Concepto y rasgos definitorios de la economia colaborativa: ¿vuelta al origen del problema?}

El análisis de la dimensión laboral de la llamada economía colaborativa, parece tener a su favor — al menos a priori — un consenso académico mayor que otros fenómenos también ligados a la descentralización productiva y fórmulas de vinculación de trabajadores. Muchos y muchas tenemos en mente las polémicas en torno al concepto de «subcontratación laboral» y sus implicaciones, pero la situación es cómodamente distinta. En aquel caso, la cuestión idiomática, el contexto socioeconómico, la estructura económica productiva concreta y el interés o asuntos ligados a estrategias políticas determinadas, dificultaban una definición más o menos universal del fenómeno. La tradición existente en algunos países en torno a alguna forma de subcontratación, actividad concreta, y/o sector de actividad ${ }^{2}$ influía en la categorización de una fórmula como "subcontratación» en sentido estricto. Así, teníamos términos diferentes como tercerización, subcontratación, outsourcing, triangulación, descentralización, deslaboralización o externalización ${ }^{3}$, que en el análisis de detalle no solo no lo hacían a la totalidad de las modalidades que acoge la sub-

2 Hace dos décadas Bronstein ilustraba bien la cuestión con casos como el francés, en el que se distingue «entre la sous-traitance para los servicios y la sous-entreprise para la mano de obra, así como "marchandage» o «mise à disposition» (de trabajadores) en función de su legalidad (1999: 429).

3 Para ejemplos en este sentido De La Garza Toledo, Enrique (2012: 13). 
contratación, sino que a veces se referían únicamente solo a una de ellas. El caso de las personas trabajadoras de la economía colaborativa salva esta dificultad, al menos de partida.

El hecho de que su aparición haya ocurrido de manera prácticamente simultánea en la economía global desarrollada facilita un «mínimo denominador común» conceptual en el plano internacional. Pese a que de nuevo tengamos varios términos, tales como economía digitalizada, economía de plataforma, gyg-economy, sharing-economy, peer economy, o uberización de la economía en referencia a esta "nueva» forma de organización de la producción, hay cierto consenso en la consideración de sus rasgos fundamentales y una distinción básica: si la actividad en concreto tiene un evidente ánimo de lucro y reproduce los mecanismos de compraventa tradicionales; o si por el contrario, el objetivo es desmercantillizar un espacio concreto y, en base a una relación entre iguales, cómo máximo rentabilizar bienes o servicios infrautilizados (sería el caso de las plataformas que ponen en contacto usuarios para compartir coche, como «Bla Bla Car», por ej.).

En ese sentido, la preocupación iuslaboralista se ha venido centrando en la primera de las acepciones expuestas, según la cual no estaríamos más allá de una digitalización de la descentralización productiva: en última instancia existe un interés empresarial, unos prestadores del servicio y unos clientes. El hecho de que el empresario sea más o menos visible, los prestadores del servicio puedan hacerlo física o digitalmente y con mayor o menor libertad de horarios y honorarios, y los clientes posean atributos de control y dirección del trabajo tradicionalmente asignados al primero, sitúa la problemática en los históricos conflictos del encaje del trabajador «atípico» en el Derecho del trabajo y las necesidades entorno a la redefinición de los elementos constitutivos de relación laboral; a saber, el debilitamiento de las notas de ajenidad y subordinación, dependencia jurídica, etérea organización empresarial autónoma, flexibilidad de las condiciones de trabajo - horario y tiempo de trabajo- y ampliación de los márgenes del desplazamiento del riesgo y ventura de la actividad (Gines y Fabrellas et al., 2016)

Miguel Rodriguez-Piñero Royo realiza una interesante aportación en la definición de los «trabajos 3.0», ligándolo a los cambios producidos por la red 3.0 y su relación con plataformas que gestionan el trabajo online (2016). En el análisis, el autor indica algunos ejemplos de perfiles de trabajadores y trabajadoras que, pese a compartir la misma fórmula de trabajo, poseen características muy distintas. Entre otros, habla de «Trabajadores Uberizados», para «aquellos contratados mediante plataformas de servicios de poca cualificación, con condiciones de trabajo malas y retribuciones escasas; y «Supertemps», para referirse a «aquellos de alta cualificación y cotización en el mercado que prefieren trabajar por libre, sin someterse a las exigencias y presiones de una organización productiva tradicional». Es fácil encontrar analogías con determinadas personas que se 
situaban en la esfera del trabajo régimen de subcontratación. Algo similar ocurre con las tradicionales situaciones generadas por las Empresas de trabajo temporal y las empresas multiservicios, y los nuevos "Trabajadores ocasionales» de la economia digital, con disponibilidad irregular, en función de preferencias o necesidades económicas; o con los «Pluriempleados 3.0» (multijobbing), para las personas que combinan trabajos de estas características.

Desde este prisma, no sería descabellado plantear que el desarrollo tecnológico y el desarrollo de fórmulas no-laborales de vinculación de trabajadores y trabajadoras han sido paralelos. La subcontratación laboral fue a la aparición de las Tecnologías de la Información y Comunicación 8 en adelante, TIC), lo mismo que «los trabajadores y trabajadoras 3.0» a la revolución digital (o cuarta revolución), ambos impensables sin el paraguas de una misma tendencia en la evolución de un modelo de desarrollo global de corte capitalista.

Las personas trabajadoras de la economia colaborativa, serían así en esencia fruto del acomodamiento de los fundamentos de la subcontratación laboral al «progreso» o a la digitalización de la economía; pero no sólo, como veremos en líneas siguientes.

\section{Del trabajo en red al trabajo en la red: algunos apuntes sobre lo novedoso de la organización de la producción}

En el año 2002, Monereo Pérez y Álvarez Montero, señalaban que la subcontratación laboral se había convertido "en la técnica normal de organización de la producción». Esa nueva dimensión venía dada por el hecho de que abarcaba ya «a todos los sectores y fases del ciclo productivo, hasta el hipotético supuesto, aunque no irreal, de empresa sin trabajadores (empresa vacía)»(2002: 21). Por las mismas fechas Lasierra Esteban acusaba la «tendencia creciente a sustituir la regulación laboral de las relaciones de trabajo por las relaciones mercantiles» (2003: 76) ; y algo después - aunque ya había incidido en ello en análisis anteriores - Sanguineti hacía referencia a «la sustitución del contrato de trabajo por formas externas de vinculación a los procesos productivos como premisa destacando la «masiva sustitución de relaciones de trabajo dependiente prestado de forma directa y regular por formas externas de relación con terceros para la realización de la misma actividad productiva» (2006: 221). El repaso de estos textos permite la constatación de la vigencia de la esencia de la subcontratación laboral y el encuadramiento de los trabajos 3.0 en ella. Como explica Adrián Todolí (2017):

(...) que la tecnología permita nuevas formas de subordinación —antes mediante los supervisores ahora mediante la reputación online- no parece que vaya a impedir la clasificación de estos trabajadores como laborales, siempre que esta subordinación se dé. De la misma forma, que tradicionalmente se relacione la ajenidad con 
medios productivos materiales (un coche, una moto, la fábrica o la maquinaria), no impedirá que hoy en día los medios productivos sean inmateriales - la propia plataforma digital y la marca de la empresa (o lo que es lo mismo la clientela) — la cual pertenece al empresario y no al trabajador.

Sin embargo, ello no indica que no haya nibil novi sub sole. De hecho, en los comienzos de los exámenes de la dimensión laboral de la subcontratación se hablaba de expulsión de actividades previamente existentes en la empresa o en el mercado —en el caso de empresas de nueva creación - que organizaban su producción de manera descentralizada de partida. En el caso de la gyg-economy podría tratarse de actividades cuya existencia se debe exclusivamente a este modelo de gestión del trabajo; dicho de otro modo, podría ser la propia digitalización lo que constituye el corazón de la actividad; la propia plataforma como creadora del negocio.

No obstante, aún en ese supuesto, continúan siendo válidas las conclusiones que giran en torno a viejos debates. Aunque, como ha quedado demostrado en esta nueva era digitalizada, una empresa pueda "vaciarse» del todo, en realidad —al menos en la mayor parte de los casos - continuaríamos ante lo que Rivero Lamas convino en llamar empresa «esbelta» (2000: 80), dado que existen unas «recomendaciones», unos códigos de conducta y unos mecanismos de control sobre la actividad del prestador de servicio que «alguien» elabora y efectúa .También Monereo matizaba tal «vaciamiento», según el cual, con el trabajo como factor fundamental de creación de valor, esta empresa vacía lo sería sólo desde el punto de vista formal, no existiendo como tal, y siendo en términos reales más bien «un modo de adquisición y utilización indirecta de personal laboral o autónomo» (2016: 113 y 114).

Pero ni siquiera Uber y Deliveroo, dos de los ejemplos más empleados para ilustrar la problemática laboral de la economia colaborativa, encajan en la descripción referida al caso de sectores de actividad nuevos. En primer lugar, aunque ambas basen su actividad en una plataforma digital, ninguna de las dos desarrolla una actividad que era inexistente hasta su nacimiento. Tanto el transporte de personas como el reparto de comida a domicilio constituían una realidad productiva antes de su aterrizaje — y en el primero de los casos, altamente regulado, además—. Las dos empresas establecen, empero, unas fórmulas y denominaciones distintas en su sector, unos prerrequisitos que permiten el acceso o no a la prestación de servicios a través de la plataforma - tales como la superación de un test sobre geografía de la ciudad objeto del servicio-, y unos "códigos de conducta» y/ o recomendaciones acerca de aspectos cuantitativos y cualitativos de la prestación (un mínimo de encargos, un vehículo con unas características concretas, por ej.), cuyo incumplimiento puede generar la «expulsión» de la plataforma ${ }^{4}$.

\footnotetext{
4 «Uber cuenta con un Manual del conductor en el que se expresa el deseo de aquélla de que los conductores acepten todas las ofertas, reservándose el derecho de investigar los motivos por los que
} 
La segunda de las diferencias más relevantes con respecto a las fórmulas clásicas de subcontratación laboral son las características de tales "proveedores» externos. Por un lado, si bien los agentes que conformaban el trabajo en red y la transformación del proyecto empresarial superando la estructura de grupos de empresas y empresas definidas, podían ser muy variopintos y con largas cadenas de relación entre sí, esta estructura se ha homogeneizado en la economía colaborativa. Donde antes se hallaban relaciones verticales y horizontales entre una nebulosa de microempresas, empresas grandes, empresas medianas y personas trabajadoras independientes, hoy tenemos una plataforma digital y un ejército de trabajadores y trabajadoras aparentemente «autónomas». De ahí, que gran parte de los juristas laborales hayan dedicado no pocos esfuerzos al análisis del encuadre de las personas trabajadoras de la economía colaborativa en las figuras de "falsos autónomos» y "autónomos dependientes». O, dicho de otra forma, se ha pasado del outsourcing al crowdsourcing (Anna Ginés y Fabrellas et al., 2016) ${ }^{5}$.

Por otro lado, y como ya adelantaba el título de este epígrafe, este camino que transita desde el "trabajo en red» hacia el "trabajo en la red», se caracteriza también por la definitiva superación de las fronteras estatales que supone la combinación de lo intangente de lo digital y lo transnacional de sus prestaciones (Rodriguez Piñero, 2016). Del "país de autónomos» que Naomi Klein avanzaba en 1999 en su libro superventas No Logo a unos pretendidos «autónomos sin país», pero con sus cualidades intactas aun tratándose de un contexto distinto al actual: «en general, el trabajo autónomo tiene lo peor de ambos mundos: es monótono, está mal pagado y no permite coordinar bien los encargos» (301 y 303).

\section{Contexto socioeconómico del desarrollo de la economía colaborativa e influencia de la Empresa Transnacional}

Como es sabido, la complejidad de la estructura de la Empresa Transnacional (en adelante, ET) y la generalización del empleo de la subcontratación, son factores que han venido retroalimentándose en el desarrollo del actual escenario de ca-

\footnotetext{
se rechaza la oferta por parte de los conductores bajo la amenaza o advertencia de desactivar a éstos cuando se hayan rechazado un número determinado de servicios. Quiere ello decir, entonces, que la autonomía sobre el trabajo a realizar por parte de los conductores se ve reducida o limitada como consecuencia de la amenaza que implica para éstos el hecho de ser desactivados (¿despedidos?)» (Trillo Párraga, 2016:13).

5 «Aparece, así, el primer impacto de estas plataformas virtuales sobre el modelo de relaciones laborales: el crowdsourcing. Esto es, la descentralización de un servicio hacia un gran número de personas en forma de llamamiento o convocatoria, únicamente posible gracias a las nuevas tecnologías. Gracias a esta forma de prestación de servicios, estas plataformas virtuales consiguen que pueda desarrollarse una actividad completamente mediante trabajadores autónomos, prescindiendo — supuestamente (...)—,de la relación de trabajo subordinado» (Anna Ginés y Fabrellas et al, 2016: 7)
} 
pitalismo global, nutriendo sin límites la desprotección de los trabajadores. Así, Garmendia definía la actual ET como una «entidad articuladora de prestaciones, es decir, en un conjunto de contratos organizados» (2016: 164); Hernández Zubizarreta destacaba su capacidad para "participar o controlar empresas o grupos de empresas» $\mathrm{y}$ "tener su domicilio en uno o varios países, en el de la empresa matriz, en el de la implantación principal o donde haya sido registrada» (2009: 296); y Sanguineti que además... «el empleo de técnicas de vinculación con terceros les permite acceder a los resultados del desarrollo de la actividad productiva de diversos grupos de trabajadores sin mantener con ellos ningún tipo de vinculación directa» (2008: 448). No es difícil advertir que, con tales axiomas, la economía colaborativa encarna a la perfección el sueño de la gran corporación.

En un artículo publicado en abril de este mismo año por El Salto Diario, Genoveva López explicaba los vínculos entre la economía colaborativa y la ET mostrando "De quién es la economía colaborativa» (2019). La autora, hacía algunas revelaciones sobre UBER:

En pocos días saldrá a bolsa y, por ahora, parece que solo se mantiene debido a las mil millonarias inyecciones de dinero que recibe por parte de empresas de capital riesgo como Founder Colletive y Crunch Fund, bancos como Goldman Sachs, Morgan Stanley o Citigroup, gigantes de la tecnología como Google o Baidu, o grandes inversores como Jeff Bezos —el fundador y director ejecutivo de Amazon-, Troy Carter — de Spotify— o Scott Banister — de Paypal—. También aparecen fondos públicos de inversión como el de Arabia Saudí, que invirtió a través de su capital riesgo SBT más de 3.500 millones de dólares, o Qatar, que, a través de su Qatar Investment Authority, invirtió más de 1.200 millones.

La autora, presenta un esquema similar sobre Lyft, empresa estadounidense que opera en el mismo sector que UBER:

Se fundó en 2012 con un capital semilla de 300.000 dólares y en la actualidad ha recibido inversiones por valor de casi 6.000 millones de dólares por parte de inversores privados como Jaguar, Land Rover, diversos fondos de inversión o el fondo de inversión público de pensiones de Canadá.

Entre los factores que han promovido la expansión de estas fórmulas de trabajo, no encontramos, asimismo, muchas novedades más allá de las que suponen la consolidación de los elementos que facilitaron la expansión de la subcontratación laboral. En ese sentido, «los trabajos 3.0» representan el triunfo de los dogmas empleados para la promoción de la subcontratación, maquillados con el aire de modernidad que otorga lo digital y la magia de las redes sociales: la necesidad de la flexibilidad y elasticidad de la mano de obra constituye una realidad incuestionable; las potencialidades de las TIC, materializadas en la revolución digital; y la incertidumbre del entorno evidenciadas, en parte importante al menos, por la influencia que ejerce sobre los mercados el panorama informativo y comunicativo del elemento anterior. 
Sin embargo, convenimos con Trillo Prárraga (2016: 6 y 7) en la importancia de contextualizar la aparición del término "economía colaborativa» hacia el año 2007. Entonces continuaban incrementándose los precios de forma progresiva, existía una precarización de las condiciones de vida como consecuencia de la también precarización laboral, y las familias enfrentaban un alto endeudamiento debido a las dificultades de acceso a determinados bienes como es el de la vivienda.

El análisis circunstancial anterior, revela, quizás, una diferencia fundamental con respecto a fenómenos ligados a la subcontratación laboral. Siendo difícil establecer el origen de la subcontratación laboral, tanto en su nacimiento como en su expansión posee un peso específico la influencia de la gran corporación -las experiencias de compra de empresas públicas en «0 Kms», o las reformas normativas operadas ex profeso para el aterrizaje de una ET son un claro ejemplo de ello-; la economía colaborativa, sin embargo, nace desde la ciudadanía debido a unas determinadas necesidades sociales, siendo después fagocitada por aquélla. Así, los discursos que incentivaban las políticas de promoción y extensión de la descentralización productiva provenían del interés de la ET, se concretaban en el establecimiento de unos objetivos vinculados a la flexibilidad y competitividad técnica y productiva, y se materializaban en la configuración de un marco normativo laboral flexible al extremo que permitiera el empleo de estas fórmulas de vinculación de trabajadores con la menor de las responsabilidades legales. En la actualidad, tales discursos han sido fortalecidos gracias a la idea de las bondades de una modernidad que, además, es inevitable: en unas condiciones de vida precarias laboral y económicamente hablando, la economía colaborativa ofrece la posibilidad de combinar varios trabajos, conciliar vida personal y familiar, y hasta de explorar las oportunidades de negocio que ofrece un mercado cambiante, y quizás convertirte en un exitoso emprendedor.

No obstante, la economía colaborativa ha radicalizado las ventajas que perseguía la ET por medios subcontratadores. La idea de «un trabajo muy acomodable y disponible con toda facilidad a los requerimientos del momento sin costes de reserva» (Monereo Pérez et al., 2006: 6), alcanza su máxima expresión en cada una de sus dimensiones:

1. Deliveroo traduce en una hora la ansiada flexibilidad laboral y elasticidad de la mano de obra, en términos de armonización de las plantillas laborales según las necesidades cualitativas y cuantitativas de la empresa -ajustando el volumen de empleo según las variaciones del mercado (Rivero Lamas, 2000: 27) -.

2. El ejército de trabajadores aparentemente independientes de Glovo, encarna el pretendido desplazamiento de funciones a un mercado con menores precios, a costa de una mano de obra normalmente más barata (Montoya Medina, 2004: 39)

3. Uber materializa la reconfiguración de la relación de poderes - a favor del capital — que supone la segmentación de la clase trabajadora y, por 
ende, su debilitamiento ${ }^{6}$. El caso concreto de los llamados VTC ofrecería otra dimensión a este hecho, a la luz de la guerra abierta que ha mantenido con las personas trabajadoras del sector del Taxi. No obstante, en general, la desmembración empresarial y fragmentación de plantillas sitúan a la empresa en una posición de superioridad frente a los trabajadores y trabajadoras, a priori porque desaparece o se debilita la actuación de sus representantes legales desde el momento en que la regulación deslaboraliza la figura o condiciona su poder al tamaño de la empresa y/o plantilla. O peor aún, según algunas jurisdicciones una actuación colectiva puede ser vulneradora del Derecho de la Competencia.

4. Todas las empresas de la economia colaborativa transfieren los riesgos y las obligaciones derivadas de su dimensión laboral. Se trata pues de un ejercicio de desresponsabilización sostenido fundamentalmente sobre dos vértices estrechamente ligados entre sí: a) el jurídico, al escapar del «incómodo» marco normativo laboral, por la confusión que genera en atención a derecho la naturaleza de los contratos ejecutados y la pluralidad de sujetos que participan de esta relación — más aún cuando sucede en ámbitos que superan los límites estatales y entra en juego el principio de extraterritorialidad de la norma con sus vicisitudes, ; y $b$ ) y el propagandístico o mercadotécnico, al facilitar la evasión de la temida publicidad negativa al aparentar al margen de las características bajo las que se desarrolla la prestación del servicio.

En definitiva, los aspectos mencionados muestran una economía colaborativa tan a disposición del capital como la subcontratación laboral, al permitir una eficiencia económica extrema a costa de la absoluta desresponsabilización corporativa incrementando —o cuanto menos, sin arriesgar — la generación de beneficios de la empresa.

\section{Los mecanismos de (des)control internacional de la subcontratación laboral como maco regulador de la economía colaborativa}

\subsection{El papel de los Estados y los organismos internacionales en la desprotección de las personas trabajadoras}

En general, los gobiernos han ido progresivamente fortaleciendo el desarrollo de técnicas de la subcontratación laboral a escala global desde diversas áreas de intervención. La externalización sistemática de servicios públicos puede ser

\footnotetext{
${ }^{6}$ Uriarte y Colotuzzo inciden en que «de ahí al empeoramiento de las condiciones de trabajo hay solo un paso, paso que no solo se da muy frecuentemente, sino que además, en muchas ocasiones es el objetivo perseguido o uno de los objetivos perseguidos» (Uriarte y Colotuzzo, 2009: 18)
} 
un reflejo literal de la aportación a esta práctica de las administraciones públicas, tendencia agravada por la crisis y las políticas de contención del gasto público desarrolladas por los Estados (Nores Torres, 2014).

Asimismo, como decíamos en el apartado anterior, en el marco de la globalización y la financiarización de la economía, el fomento de las políticas de atracción e Inversión Extranjera Directa se ha traducido durante las últimas décadas en reformas normativas internas basadas en la flexibilidad y desregulación laboral, ejes hoy de la economía colaborativa. Además, la recesión económica y la presión de los organismos internacionales han acelerado las reformas del marco normativo general de las relaciones laborales - abaratamiento del despido, proliferación de contratos basura, modificación de condiciones sustanciales del contrato, etc.avalan figuras concretas como el empoderamiento del emprendedor.

Con la vocación clara, los Estados, por medio de estas reformas, han abonado bien el espacio de las fórmulas deslaboralizadoras, pero además, eventualmente se han servido de medidas coadyuvantes, tales como las limitaciones de normas de protección de los trabajadores y trabajadoras — como la subrogación empresarial o sustitución patronal - y otras políticas o programas específicos, aparentemente dirigidos a colectivos vulnerables, pero que pueden esconder tras de sí aún más facilidades para el desarrollo de estos modelos de contratación: es el caso del ensalzamiento de la figura del emprendedor o del «empresarismo" - denominación latinoamericana-. Bien es cierto que históricamente, también las empresas han manipulado muy acertadamente la percepción positiva de las figuras mercantiles ligadas a la subcontratación -resaltando su carácter instrumental de introducción y formación en la empresa en cuestión, las bondades de la autonomía, de la independencia laboral, etc.) y la digitalización de la economía y la precarización de las condiciones de vida han fortalecido esta idea, a veces como única alternativa posible para la supervivencia.

Junto a las mencionadas reformas, los Estados han participado del desarrollo de mecanismos subcontratación de forma más o menos voluntaria por la vía de los organismos internacionales. Los procesos de integración regional, los tratados de libre comercio y las instituciones internacionales de las que son parte encarnan la firme connivencia de éstos con la ET en el desarrollo del capitalismo, y de la subcontratación laboral como uno de los instrumentos más eficaces para debilitar los derechos de los trabajadores y trabajadoras.

Por un lado, las instituciones económico-financieras globales han sido históricamente herramientas de coacción y estrangulamiento de los derechos de las mayorías sociales en el seno de los países, por la vía de la imposición de políticas de ajuste originadas por agresivos procesos de endeudamiento. La influencia de la Organización Mundial del Comercio, el Fondo Monetario Internacional y el 
Banco Mundial en el debilitamiento del Estado como garante de derechos de los trabajadores y las trabajadoras se refleja bien en su promoción de la flexibilización de las legislaciones, los procesos de privatización de sectores públicos y en general la adopción de políticas nacionales subordinadas a los principios neoliberales.

Este adelgazamiento de la intervención del Estado en la economía y la apertura de fronteras comerciales ha sido paralelo a la profundización de los procesos de integración regional y aumento de los tratados comerciales bilaterales y regionales, lo que ha transformado la subcontratación laboral en un fenómeno estructural. Por un lado, a la facilidad de desresponsabilización que otorga la dificultad que entraña la libre circulación de mercancías y capitales a la hora de identificar a los verdaderos responsables de los abusos laborales y violaciones de derecho fundamentales, hay que añadirle la «invisibilidad» que ofrece ésta al digitalizarse; por otro, las transformaciones propiamente normativas impulsadas desde los espacios transnacionales han sido definitivas: mientras asistíamos a un proceso de desregulación laboral en los terrenos nacionales, en los internacionales se sucedía una producción normativa comercial más poderosa económica y políticamente y en concreto, con una firme exigibilidad jurídica vía tratados comerciales y regulaciones provenientes de sus instituciones

\subsection{El soft law como espacio regulador de la economía colaborativa}

Lo cierto es que más allá de las políticas concretas que los Estados han llevado a cabo para el desarrollo del recurso a la subcontratación y fórmulas deslaboralizadoras como las fomentadas por determinados modelos de economía colaborativa, en términos generales, encontramos una identificación de éste con sus dueños - la ET - toda vez que éste otorga subvenciones, apoyo político, diplomático y lobby para su internacionalización y todo lo relacionado con ella; hasta tal punto que los conflictos y vicisitudes de su desenvolvimiento son considerados política de Estado. Así, el escenario normativo asimétrico entre el derecho comercial global y los derechos laborales perjudicados por estos fenómenos ha sido participado por el Estado toda vez que ha permitido que las obligaciones de las ET se ajusten a su territorio — previamente debilitado para ello- y los derechos a un terreno supranacional mandado por instituciones internacionales y tratados regionales, bilaterales y multilaterales con fuerza coercitiva superior para hacerlos exigibles (Hernández Zubizarreta et al, 2016: 20, 25 y 26).

Es ese orden de ideas el que explica la ausencia de regulación internacional en materia de una subcontratación laboral que ha servido de base normativa para el desarrollo de los trabajos 3.0. La OIT, máxima autoridad laboral en el ámbito internacional, únicamente alcanzó a elaborar un "Proyecto de Recomendación sobre el trabajo en régimen de subcontratación» concebida por su Conferencia entre 1997 y 1998. Ello fue en parte debido a la naturaleza jurídicamente escurridiza de la subcontratación laboral, pero también por razones ligadas a la bicefalia mercantil y laboral del fenómeno, 
a circunstancias consustanciales a las características del fenómeno y a las dificultades añadidas por la vertiente internacional, sus tradiciones y modelos productivos. Pese a que algunos de esos elementos no se dan, o lo hacen de manera menos relevante en el caso que nos ocupa, la OIT ha integrado las preocupaciones de la subcontratación en torno a las cadenas mundiales de suministro (2016) y ha centrado las de la economía colaborativa en el marco del «Futuro del trabajo» ${ }^{7}$.

En estricta relación con la justicia, la debilidad de los órganos judiciales de algunos de los Estados en los que opera el «trabajo 3.0», dificulta de partida cualquier intento real de llevar un caso de abuso laboral. Es importante notar que tal «debilidad» no hace referencia exclusiva a las tradicionalmente presentes en algunas economías, sino que tienen que ver con el contexto marcado por la crisis de 2008 y su gestión: a la precarización vital de las personas trabajadoras —elemento de por sí desmotivador para el litigio — hay que sumar una justicia predispuesta a la privatización — a saber, con unas tasas de acceso «in crescendo" - y a menudo particularmente desprestigiada.

De forma paralela, el Derecho Corporativo Global cuenta con efectivos laudos emitidos por los tribunales arbitrales frente a un Derecho Internacional del trabajo carente de garantías y efectividad jurídica. Mientras el derecho internacional público solo le es aplicable a las ET a través de los Estados, los sistemas de arbitraje contemplados en el engranaje de la lex mercatoria ostentan un poder coercitivo tal que contempla sanciones que incluyen desde cuantiosas indemnizaciones o imposición de modificaciones legislativas, hasta el bloqueo económico internacional. La Corte Permanente de Arbitraje de la Haya, la corte de arbitraje de la cámara de Comercio Internacional, el sistema de solución de diferencias de la Organización Mundial del Comercio o el Centro Internacional de Arreglo de Diferencias relativas a Inversiones (CIADI) del Banco Mundial representan asimismo la privatización de la justicia expuesta en líneas anteriores.

Los tratados de libre comercio, por su parte, poseen un peso específico en el empoderamiento del derecho Comercial Global y no solo por engrosar el panorama de los tribunales arbitrales, sino también por su aguerrida intervención en los marcos normativos nacionales a través de un proceso explícito de convergencia reguladora. En este sentido, el objetivo del TTIP, el TISA y el CETA (siglas en inglés de Transatlantic Trade and Investment Partnership,

7 Es el caso de las importantes contribuciones sobre la materia que aportan títulos como «Derecho y trabajo en la era digital: ¿"revolución industrial 4.0" o "economía sumergida 3.0”?» (Molina Navarrete, 2107), «Economía colaborativa y laboralidad: los cabos sueltos entre el vacío legal y la dudosa legalidad» (Vallecillo Gámez, 2017) o "Generalización tecnológica: efectos sobre las condiciones de trabajo y empleo» (San Martín Mazzucconi,2017), enmarcados en la sección de Futuro del Trabajo de la web del organismo. 
Trade in Services Agreement y Comprehensive. Economic Trade Agreement respectivamente) es una mutua adaptación de la normativa interna de las partes intervinientes en los tratados, una armonización que necesariamente ha de producirse a la baja para dar cumplido a la idea central de los acuerdos: eliminar toda aquella regulación que represente un obstáculo al mercado (Guaman, 2015: 93). Esta convergencia representa de hecho uno de los ejes del TTIP, afecta a todas las facetas reguladoras internas y cuenta con una herramienta propia para su construcción: el Consejo de Cooperación Reguladora, una especie de órgano legislativo supranacional con un papel determinante en la rebaja de los estándares laborales; es lo que Adoración Guaman conviene en denominar la «americanización» de los derechos laborales (2015: 112-117), cuyo objetivo es la protección del capital, pero con efecto directo sobre la ciudadanía y sin ninguna clase de control democrático.

Frente al descrito empoderamiento de la lex mercatoria, o incluso paralelamente a ella, ha ido prosperando la idea de la Responsabilidad Social Corporativa-en adelante, RSC-, como mecanismo que equilibra la asimetría normativa descrita. Se trata de una fórmula de Soft Law-Derecho Blando-, unilateral — nacida de la propia empresa-, voluntaria y sin mecanismo coercitivo alguno. No ha de perderse de vista que su surgimiento deriva de la sistemática negativa de las empresas a la aceptación de códigos normativos vinculantes, creados ad hoc para su control y limitación de su poder, por lo que estas características parecen coherentes con los intereses corporativos, y explican en gran medida su afianzamiento en la sociedad y sus transformaciones.

Así, y a la luz de las vinculaciones Estado-Empresa descritas en las líneas precedentes, tampoco resulta extraño que haya sido este mismo el rasgo caracterizador de la regulación de la subcontratación — si bien es cierto que, como ya ocurrirá en el caso de la OIT, en la Unión Europea se ha ido centrando en las cadenas globales de suministro-. A pesar de que la década de los 90 supuso la decidida confirmación de la RSC de la mano del Global Compact (Pacto Mundial) de la ONU, sus predecesoras Lineas Directrices para Empresas Multinacionales de la OCDE (de 1976, revisado en el año 2011), y Declaración Tripartita de Principios sobre las Empresas Multinacionales y la Politica Social de la OIT (adoptada en 1977 y enmendada por tercera vez en marzo de 2017) marcaron bien la tendencia. Así, el soft law corroboró su espacio como mecanismo de regulación de la materia a través del Libro Verde Sobre la responsabilidad social de las empresas de la Comisión Europea (2001), las Normas sobre las Responsabilidades de las Empresas Transnacionales y otras Empresas Comerciales de la ONU (2003), los Principios Rectores sobre las Empresas y los Derechos Humanos publicados por la ONU en el año 2011, y la Estrategia renovada de la UE para 2011-2014 sobre la responsabilidad social de las empresas. 
El Observatorio de las Multinacionales en América Latina, resume bien la cuestión: «No se trata, ni mucho menos, de que la RSC sea la causa de la tercerización: lo que sí sucede es que este paradigma sirve para continuar y profundizar con la dinámica de la externalización de tareas en las grandes corporaciones» (OMAL, 2013).

\subsection{Límites de la acción protectora de los marcos supranacionales y tendencias en regulación internas en la actualidad}

En el ámbito internacional, se puede decir que la cuestión está aún en una fase de exploración inicial, en la que las instituciones alertan de importancia económica y social — más la primera que la segunda, como veremos en adelante- de la economía colaborativa, investigan y diseminan sus implicaciones conceptuales, y tratan de redimensionar el tablero normativo.

La OCDE, en un informe sobre «Nuevas formas de trabajo en la economía digital»(2016), se limita únicamente a identificar algunas cuestiones clave del asunto, entre las que destacan las relativas al estatus jurídico, tareas y capacidades del proveedor, los principios fundamentales y derechos de los trabajadores, la evaluación de los marcos regulatorios y el papel autorregulador de las plataformas - vía reputación on-line y competencia entre proveedores-.

En la UE, la Comisión Europea, el Comité de las Regiones Europeo, el Parlamento Europeo y el Consejo Económico y Social Europeo (CESE), han aportado algunas líneas en un sentido similar. La Comisión ha venido reproduciendo los discursos clásicos alrededor de la creación de empleo, la innovación emprendedora y la oportunidad que representa para las personas trabajadores contar con un empleo altamente flexible y acomodable a las circunstancias vitales. Así, si bien ha liderado iniciativas como la creación de un sistema de resolución de litigios rápido (el RAL, acrónimo de Resolución Alternativa de Litigios) que ataje los problemas relacionados con el consumo en la economía de plataformas o realice seguimientos de las potencialidades económicas de los sectores relacionados con ella, en lo laboral se ha limitado a proporcionar orientaciones sobre la aplicación de la legalidad vigente en la UE, remitiendo a la normativa interna y acaso a la jurisprudencia europea para la determinación de la existencia o no de relación laboral.

En un sentido similar ha venido trabajando el Comité de las Regiones. El Comité, en un Dictamen sobre la Dimensión Local y Regional de la Economía Colaborativa (DOCE C 51 d 10 de febrero de 2016, p.29), asume en cierto modo los riesgos en materia laboral que las empresas con «ánimo de lucro" (sic) inscritas bajo el paraguas "colaborativo", aunque confiando en los mecanismos de autorregulación que ofrecen cuestiones como la confianza y la reputación de la marca. Igual posicionamiento sobre la importancia de los códigos de conducta ofrece el CESE. En su dictamen «La eco- 
nomía colaborativa y la autorregulación» (DOCE C 303 de 19 de agosto de 2016) incide en la conveniencia de ensanchar el espacio de autorregulación de estas organizaciones sin injerencia alguna por parte de instituciones europeas o estatales.

El Parlamento Europeo, por su parte encomienda a la comisión la revisión y el análisis de la normativa europea y estatal sobre la economía colaborativa, planteando una eventual necesidad modernizadora de la legislación social y laboral a fin de preservar los derechos laborales y los sistemas de bienestar social también en el mercado de trabajo digital. No obstante, destaca la responsabilidad y competencia de los Estados miembros en materia de protección social y mantiene la senda del soft-law al remarcar la relevancia de políticas de buenas prácticas en la UE y a escala internacional en el asunto.

Ante esas tendencias autorreguladoras, convenimos con Emilia Castellano Burguillo en la urgencia de una regulación "que proporcione un marco regulador sólido" y fije "garantías para las condiciones de empleo y trabajo de los trabajadores de la economía colaborativa» que fuera completado por la actuación de los entes de ámbitos geográficos inferiores (2017: 271). Los pronunciamientos de la Comisión Europea y del TJUE ${ }^{8}$ acerca de la laboralidad de determinadas fórmulas, podrían ser un preludio de esa ambición, pero lo cierto es que el empleo de criterios de remuneración en atención a la condición de «marginal» o «accesoria» de ésta, mantienen un espíritu limitador, y hoy el espacio de protección de las personas trabajadoras de la economía digital continúa siendo el marco estatal.

La negación del carácter de trabajadores por cuenta ajena de los conductores de UBER por parte de la empresa, ha sido corregida por los tribunales de distintos países, y sin marcos normativos comunes al respecto: Alemania, Dinamarca, EEUU y Reino Unido han evidenciado la laboralidad de los prestadores del servicio obligando a la empresa al sometimiento de la legalidad laboral. En el Estado español, el Juzgado de lo Social n. ${ }^{\circ} 1$ de Madrid en Sentencia n. ${ }^{\circ} 130$ de 2019 de 4 de abril concluyó la laboralidad de la relación que une Glovo con los repartidores (riders) y asignó la aplicación del convenio colectivo del sector del Trasporte declarar que la actividad principal es el transporte, en la categoría de Mozo y no la intermediación o la prestación de servicios de la sociedad de la información ${ }^{9}$. A su vez, la sentencia señala que corresponde la categoría de Mozo

\footnotetext{
8 Comunicación de la Comisión al Parlamento europeo, al Consejo, al CESE y al Comité de las Regiones "Una agenda europea para la economía colaborativa», Documento COM (2016) 356 final de 2 de junio de 2016, p.14; y STJUE 232/09 DANOSA Dita Danosa y LKB Lizings SIA, de 11 de noviembre de 2010 y STJUE C-413/01 Franca Ninni-Orasche y undmnisiter fur Wissenchaft, Verkher und Kunst, de 6 de noviembre de 2003, citadas en íbid. págs. 275-277.

9 Para un análisis de la sentencia ver el blog de Adrían Todolí Signes en https://adriantodoli. com/category/economia-colaborativa/
} 
debido a las funciones del rider. Esta sentencia, ya contaba con el precedente de las actas de la Inspección de Deliveroo en Valencia, Madrid y más recientemente Barcelona, que se manifestaban en el mismo sentido

\section{Conclusiones}

La economía colaborativa, en la versión que la interpreta en base a prácticas empresariales, posee al menos los elementos más importantes de otrora debatidas cuestiones relacionadas con la subcontratación laboral. De hecho, la mayor parte de las diferencias entre una y otra vienen dadas por las implicaciones del desarrollo de una actividad fuertemente digitalizada, pero mantienen un mismo objetivo: el desplazamiento del riesgo y ventura empresarial hacia las personas trabajadoras o prestadoras del servicio; la desresponsabilizacíon de las obligaciones laborales y el incremento de sus obligaciones; la mercantilización del trabajo.

Siendo este el objetivo el expresamente manifestado por la gran corporación —bien a través de lobby, bien a través de sus propias prácticas—, no resulta difícil adivinar la presencia de las ET en la economía colaborativa. Esta presencia, sitúa al trabajo 3.0 en un contexto global marcado por el poder corporativo y una decidida asimetría normativa entre la lex mercatoria y todo lo que tiene que ver con la protección de social de la ciudadanía; obviamente, en detrimento de esta última.

En esta esfera, la economía colaborativa se encuentra con un terreno internacional abonado para el desarrollo y generalización de prácticas de subcontratación laboral que han supuesto un importante grado de desprotección de las personas trabajadoras. De hecho, no sería descabellado afirmar que ha sido precisamente esa circunstancia la que ha generado el auge del a economía de plataformas.

En ese sentido, destaca que la senda normativa de la regulación de la economía colaborativa haya sido la misma que para la subcontratación, y ello pese a salvar algunas de las dificultades que enfrentaba aquélla - existe más consenso en torno al concepto y las implicaciones de este modelo de producción, o sus necesidades regulatorias- - Los mecanismos de autorregulación y los códigos de conductas han sido así la propuesta más repetidas desde organismos supranacionales, al tiempo que los tribunales han dado la batalla en el terreno estatal.

Estos dilemas y su solución legislativa, alcanzan el principio básico tutelar del Derecho del Trabajo, planteando de nuevo si éste debe adaptarse a los mercados y no obstaculizar su "desarrollo», si la normativa debe modernizarse para dar cumplida respuesta a los desafíos planteados por estas nuevas modalidades de trabajo, o si ya existen en los ordenamientos normas suficientes para tal cobertura. 


\section{Bibliografía}

Bronstein, Arturo (i999): «La Subcontratación Laboral» Revista Derecho Laboral, Tomo XLII N. ${ }^{\circ} 195,429$.

De La Garza Toledo, Enrique (2012): La subcontratación y la crisis capitalista Revista Trabajo, núm-9.

Ermida Uriarte, Oscar y Colotuzzo, Natalia (2009): Descentralización, Tercerización, Subcontratación, Oficina Internacional del Trabajo, Lima; también disponible en http://white.oit.org.pe/proyectoactrav/pry_rla_06_m03_spa/publicaciones/documentos/estudio_descentralizacion_tercerizacion_subcontratacion.pdf

GARMEndia, Mario (2006): «La nueva consideración de la empresa y su influencia sobre la caracterización de las relaciones laborales», Derecho del Trabajo, 2.

Ginès i Fabrellas, Anna y Gálvez Duran, Sergi (2016): «Sharing economy vs. Uber economy y las fronteras del derecho del trabajo: la (des)protección de los trabajadores en el nuevo entorno digital», InDret: Revista para el Análisis del Derecho, 1,1-44.

Guaman, Adoración (2015): TTIP. El asalto de las multinacionales a la democracia, Madrid, Ediciones Akal

Hernández Zubizarreta, Juan (2009): Las empresas transnacionales frente a los derechos humanos: Historia de una asimetría normativa. De la responsabilidad social corporativa a las redes contrahegemónicas transnacionales, Bilbao, Hegoa.

Hernández Zubizarreta, Juan y Ramiro, Pedro (2016): Contra la lex mercatoria: Propuestas $y$ alternativas para desmantelar el poder de las empresas transnacionales, Bacelona, Icaria.

Klein, Naomi (1999): No Logo. El Poder de las marcas, Barcelona, Paidós.

Lasierra Esteban, Jose Manuel (2003): «La dimensión económica de la descentralización productiva», Descentralización productiva y responsabilidades empresariales. El "Outsourcing», Navarra, Aranzadi

López, Genoveva ( 2019): «De quién es la economía colaborativa», El Salto Diario, disponible en https://www.elsaltodiario.com/economia/duenos-economia-colaborativauber-airbnb

Molina Navrrete, Cristobal (2107): «Derecho y trabajo en la era digital: ¿"revolución industrial 4.0" o "economía sumergida 3.0"?», disponible en https://www.ilo.org/ma$\mathrm{drid} /$ fow/trabajo-y-la-produccion/WCMS_548619/lang--es/index.htm

Monereo Pérez, Jose Luis y Álvarez Montero, Alberto (2002): Dimensión laboral de la contratación y subcontratación empresarial, Granada, edit. Comares.

Monereo Pérez, Jose Luis (20 i6): «La garantía de los derechos de los trabajadores en la subcontratación empresarial», Derecho de las relaciones laborales, 2.

Montoya Medina, David (2004): Trabajo en contratas y protección de los trabajadores, Valencia, Tirant lo Blanch

Moruno, Jorge (2015): La fábrica del emprendedor. Trabajo y politica en la empesa-mundo, Madrid, ediciones Akal.

Nores Torres, Luis Enrique (2014) : «El empleo público en tiempos de crisis: la descentralización productiva en las AA.PP», Revista General de Derecho Administrativo ,n35, Iustel, 2014, disponible en http://www.iustel.com/v2/revistas/detalle_revista.asp?id=1

Observatorio de Multinacionales en América Latina (2013): «Extendiendo la tercerización", en http://omal.info/spip.php?article 5832

OCDE (2016): New Forms of work in the digital economy, disponible en https://www. oecd-ilibrary.org/science-and-technology/new-forms-of-work-in-the-digitaleconomy_5jlwnklt820x-en 
Oficina Internacional del Trabajo (1997): Informe VI (1) Trabajo en régimen de subcontratación, 85. a reunión de la Conferencia Internacional del Trabajo, Ginebra.

Oficina Internacional del Trabajo (20i6), Informe IV, El trabajo decente en las cadenas mundiales de suministro, Ginebra.

Ortí Vallejo, Antonio y Rubio Gimeno, Gemma (2019): Propuestas de Regulación de las Plataformas de Economía Colaborativa: Perspectivas General y Sectoriales, navara, Aranzadi.

Parlamento Europeo (20 I 5): «Hacia un mercado único digital», disponible en https:// eur-lex.europa.eu/legal content/ES/TXT/HTML/?uri=CELEX:52016IP0009\&from $=\mathrm{EN}$

Rivero Lamas, Juan (2000): «La descentralización productiva y las nuevas formas organizativas de trabajo", Descentralización productiva y las nuevas formas organizativas de trabajo», Madrid, Subdirección General de publicaciones del Ministerio de Trabajo y Asuntos Sociales.

Rodriguez-Piñero Royo, Miguel (2016: «El trabajo 3.0 y la Legislación Laboral» en Economia Colaborativa y Derecho Social, disponible en: http://grupo.us.es/ iwpr/2016/09/10/el-trabajo-3-0-y-la-regulacion-

SANGuineti, Wilfredo (2006): "Descentralización productiva, subcontratación y calidad del empleo: ¿Términos incompatibles?», Revista de Derecho Social n. ${ }^{\circ 33 .}$

SANGuineti, Wilfredo (2008): «La tutela de los derechos fundamentales del trabajo en las cadenas de producción de las empresas multinacionales», La negociación colectiva en España: Un enfoque interdisciplinar, Madrid, Ediciones Cinca y CCOO.

SAn Martín Mazzucconi, Carolina 2017): «Generalización tecnológica: efectos sobre las condiciones de trabajo y empleo", enmarcados en la sección de Futuro del Trabajo de la web del organismo, disponible en disponibles en https://www.ilo.org/madrid/fow/ trabajo-decente-para-todos/WCMS_548618/lang--es/index.htm.

Todolí, Adrian (2017): «La economía colaborativa o economía de los falsos autónomos? disponible en https://confilegal.com/20170509-la-economia-colaborativa-o-la-economia-de-los-falsos-autonomos/

Trillo PÁrraga, Francisco (2016): Economía digitalizada y relaciones de trabajo, Revista de derecho social, N. ${ }^{\circ} 76$.

VAllecillo GÁmez, Maria Rosa (2017): «Economía colaborativa y laboralidad: los cabos sueltos entre el vacío legal y la dudosa legalidad», disponible en https://www.ilo.org/ madrid/fow/trabajo-y-la-produccion/WCMS_548607/lang--es/index.htm 